\title{
Effect of transition metal elements on the structural and optical properties of $\mathrm{ZnO}$ nanoparticles
}

\author{
I KAZEMINEZHAD ${ }^{1}$, S SAADATMAND ${ }^{1}$ and RAMIN YOUSEFI ${ }^{2, *}$ \\ ${ }^{1}$ Nanotechnology Laboratory, Physics Department, Shahid Chamran University of Ahvaz, Ahvaz, Iran \\ ${ }^{2}$ Department of Physics, Islamic Azad University (IAU), Masjed-Soleiman Branch, Masjed-Soleiman, Iran
}

MS received 29 September 2015; accepted 17 December 2015

\begin{abstract}
Undoped and transition metal (TM)-doped $\mathrm{ZnO}$ nanoparticles $\left(\mathrm{Zn}_{0.98} \mathrm{X}_{0.02} \mathrm{O}-\mathrm{NPs}, \mathrm{X}=\mathrm{Mn}, \mathrm{Cr}, \mathrm{Co}\right.$ and Fe) were synthesized from a metal nitrate precursor and gelatin by a sol-gel method. The compounds were synthesized at calcination temperatures of $550^{\circ} \mathrm{C}$ for $6 \mathrm{~h}$. The synthesized undoped/doped $\mathrm{ZnO}$-NPs were characterized by X-ray diffraction analysis (XRD) and scanning electron microscopy (SEM). XRD results indicated that the sample products were crystalline with a hexagonal wurtzite phase. SEM images showed the ZnO-NPs nearly spherical shapes and a non-uniform shape for doped ZnO-NPs. The crystalline development in the ZnO-NPs was investigated by X-ray peak broadening. The size-strain plot (SSP) method was used to study the individual contributions of crystallite sizes and lattice strain of the undoped and doped ZnO-NPs. The obtained results showed that strain of the NPs plays an important role in peak broadening; moreover, the mean crystalline size of the undoped and doped ZnO-NPs estimated from the SEM and the SSP method was highly inter-correlated. Finally, optical properties of the samples were studied by a UV-Vis spectrometer.
\end{abstract}

Keywords. TM-doped ZnO-NPs; sol-gel method; size-strain method; optical properties.

\section{Introduction}

$\mathrm{ZnO}$ is an $n$-type semiconductor with high electron mobility, a direct energy band-gap of $3.37 \mathrm{eV}$ and a high exciton binding energy of $60 \mathrm{meV}$, which is greater than the thermal energy at room temperature. $\mathrm{ZnO}$ has numerous attractive characteristics for electronics and optoelectronics devices due to its various accessibility of growth method and also due to its unique properties. $\mathrm{ZnO}$ has a good transparency and strong room temperature luminescence, so it can be considered as a promising material for different applications [1-4]. One of the best ways to improve $\mathrm{ZnO}$ nanostructure properties is doping. Therefore, to obtain better crystallization quality, optical, electrical and ferromagnetic properties, researchers have studied the effect of dopant materials on $\mathrm{ZnO}$ properties. Different reports noted that the role of the particle size, impurities, morphology, the metal oxide host system, surface defects, dopant type and dopant concentration are very important to physical properties and applications of $\mathrm{ZnO}[5,6]$. TM-doped $\mathrm{ZnO}$ can be used as magnetic materials with several applications. Therefore, study about effects of these elements on structure and optical properties of $\mathrm{ZnO}$ are very important for future applications. In addition, to achieve $\mathrm{ZnO}$ nanoparticles with specific property and application, it is necessary to select one of the several growth methods such as sol-gel [7,8], precipitation [9],

\footnotetext{
*Author for correspondence (Yousefi.ramin@ gmail.com, raminyousefi@iaumis.ac.ir)
}

solo-chemical processes [10], vapour phase transport (VPT) [11], spray pyrolysis [12], DC thermal plasma synthesis [13], hydrothermal synthesis [14] and chemical vapour deposition (CVD) [15].

In this study, a simple sol-gel method was used to synthesize undoped and TM-doped $\mathrm{ZnO}-\mathrm{NPs}$ with a narrow size distribution. The strain of the TM-doped ZnO-NPs was calculated using the SSP method. Then, the effects of the strain on the crystallinity and optical properties of ZnO-NPs were investigated.

\section{Experimental}

To prepare $\mathrm{Zn}_{0.98} \mathrm{TM}_{0.02} \mathrm{O}-\mathrm{NPs}$, zinc nitrate hexahydrate $\left(\mathrm{Zn}\left(\mathrm{NO}_{3}\right)_{2} \cdot 6 \mathrm{H}_{2} \mathrm{O}\right)$, cobalt nitrate hexahydrate $\left(\mathrm{Co}\left(\mathrm{NO}_{3}\right)_{2}\right.$. $\left.6 \mathrm{H}_{2} \mathrm{O}\right)$, manganese nitrate hexahydrate $\left(\mathrm{Mn}\left(\mathrm{NO}_{3}\right)_{2} \cdot 6 \mathrm{H}_{2} \mathrm{O}\right)$, iron nitrate $\left(\mathrm{Fe}\left(\mathrm{NO}_{3}\right)_{3} \cdot 9 \mathrm{H}_{2} \mathrm{O}\right)$, chromium nitrate $\left(\mathrm{Cr}\left(\mathrm{NO}_{3}\right)_{3}\right.$. $\left.9 \mathrm{H}_{2} \mathrm{O}\right)$, gelatin $\left(\left(\mathrm{NHCOCH}-\mathrm{R}_{1}\right)_{n}, \mathrm{R}_{1}=\right.$ amino acid $)$ and deionized (DI) water were used as starting materials. To prepare $\mathrm{Zn}_{0.98} \mathrm{TM}_{0.02} \mathrm{O}-\mathrm{NPs}$, the specific amounts of zinc nitrate and transition metal nitrate were dissolved in $30 \mathrm{ml}$ of DI water and stirred for $30 \mathrm{~min}$. Meanwhile, $10 \mathrm{~g}$ of gelatin was dissolved in $150 \mathrm{ml}$ of DI water and stirred for $30 \mathrm{~min}$ at $60^{\circ} \mathrm{C}$ to achieve a clear gelatin solution. Then, zinc nitrate and transition metal nitrate solution were added to the gelatin solution and the container was moved to a thermostatic oil bath with adjusted temperature at $80^{\circ} \mathrm{C}$. The compound solution was then stirred for $12 \mathrm{~h}$ to obtain a honey-like resin. The resin became hard after the temperature of the container was 
reduced to room temperature. The final product was calcined at $500^{\circ} \mathrm{C}$ in air for $6 \mathrm{~h}$ to achieve $\mathrm{Zn}_{0.98} \mathrm{TM}_{0.02} \mathrm{O}-\mathrm{NPs}$.

XRD (Philips, X'Pert, $\mathrm{CuK} \alpha$ ) was used to evaluate phase characteristics of the samples. The morphology of the NPs was studied using a scanning electron microscope (SEM, Quanta 200F). Elemental analyses of the products were undertaken using field emission Auger electron spectroscopy (FEAES, JAMP-9500F). UV-Vis spectroscopy (PerikinElmer spectrometer) was applied for considering the optical properties. Raman measurements (Jobin Yvon Horiba HR 800 UV) were carried out to study the crystallinity of the obtained products.

\section{Results and discussions}

Figure 1 shows typical SEM images of the undoped (figure 1a), Fe-doped (figure 1b), Cr-doped (figure 1c), Codoped (figure 1d) and Mn-doped (figure 1e) ZnO-NPs. As the figures show that the shape of the particles is approximately spherical with uniform size distribution. The size histograms of the $\mathrm{ZnO}-\mathrm{NPs}$ are shown in figure 2. According to these histograms, the average size of around $105 \mathrm{~nm}$ for the undoped and $\mathrm{Cr}$-doped $\mathrm{ZnO}, 90 \mathrm{~nm}$ for Co- and $\mathrm{Mn}$-doped and $96 \mathrm{~nm}$ for the Fe-doped ZnO-NPs.
Figure 3a shows the XRD patterns of the undoped and TM-doped ZnO-NPs. The XRD patterns are in agreement with the standard card of $\mathrm{ZnO}$ wurtzite hexagonal structure (JCPDS no. 792205). Further, the XRD patterns of all samples show no extra peak due to either any impurity or dopant compounds. The preferred orientation of all XRD patterns of TM-doped $\mathrm{ZnO}$ nanoparticles is (101). A slight shift towards the higher degree which is observed in the Cr-, Fe- and Codoped samples in comparison to that of the undoped $\mathrm{ZnO}$ NPs, while this shift occurs towards the lower degree for Mn-doped sample (figure 3b). The existence of these shifts is related to the difference between the ionic radii of the substitutes $\left(\mathrm{Cr}^{+2}(0.63 \AA), \mathrm{Co}^{+2}(0.72 \AA), \mathrm{Fe}^{+2}(0.64 \AA)\right.$ and $\left.\mathrm{Mn}^{+2}(0.80 \AA)\right)[6]$ with that of $\mathrm{Zn}^{+2}(0.74 \AA)$. These results are indirect evidence to prove the fact that some of the $\mathrm{Zn}^{+2}$ ions have been replaced by TM ions.

Wurtzite lattice parameters such as the values of $d$, the distance between adjacent planes in the Miller indices $(h k l)$ (calculated from the Bragg equation, $\lambda=2 d \sin \theta$ ), lattice constants $a, b$ and $c$, inter-planar angle $(\varphi)$ and unit cell volumes were calculated from the lattice geometry equation [16]. The lattice parameters of the samples are summarized in table 1 . The Scherrer equation is a common method to calculate crystallite size: $D=\left(k \lambda / \beta_{h k l} \cos \theta\right)$, where $D$ is the

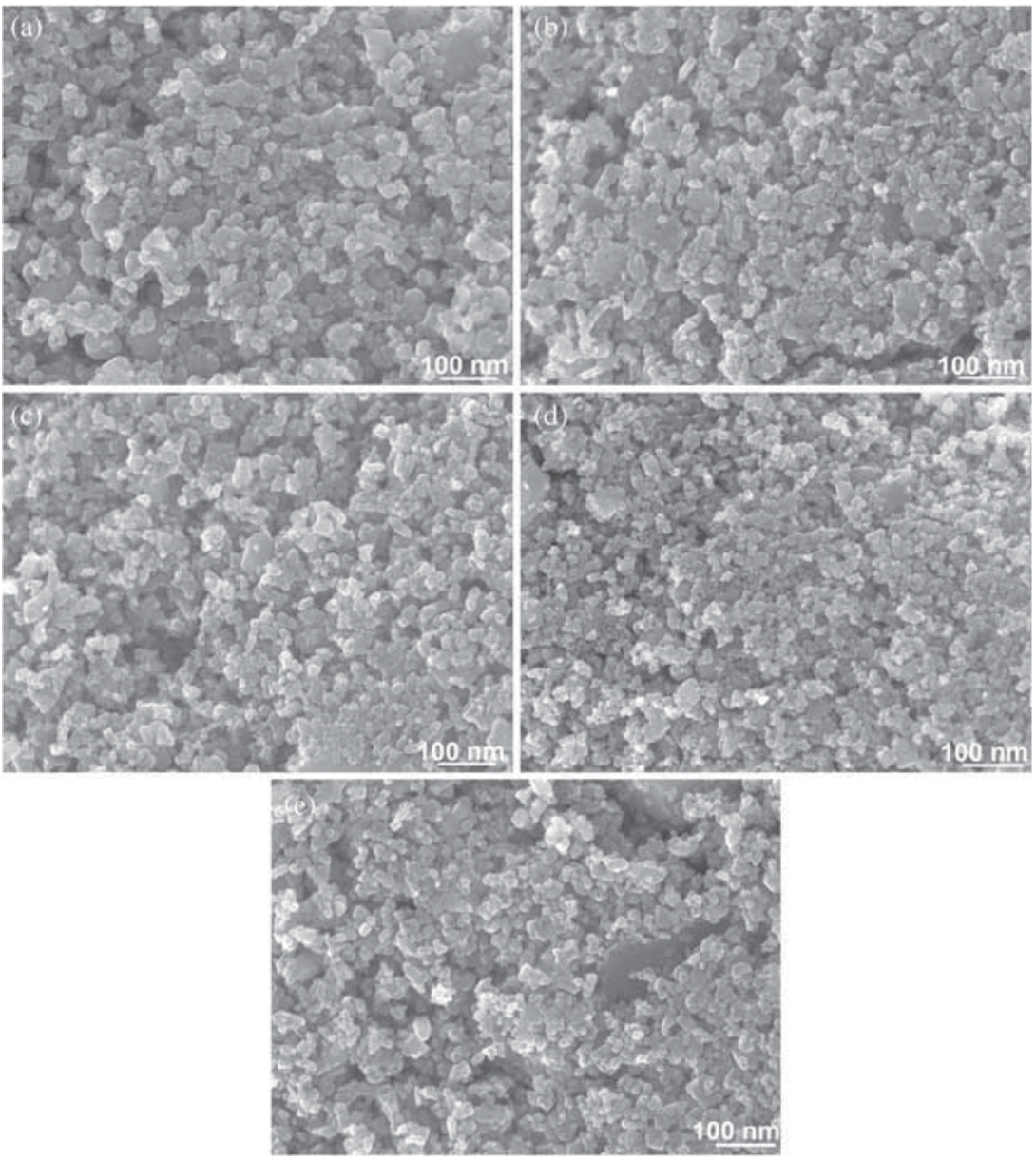

Figure 1. SEM image of (a) undoped, (b) Fe-doped, (c) Cr-doped, (d) Co-doped and (e) Mn-doped ZnO-NPs. 

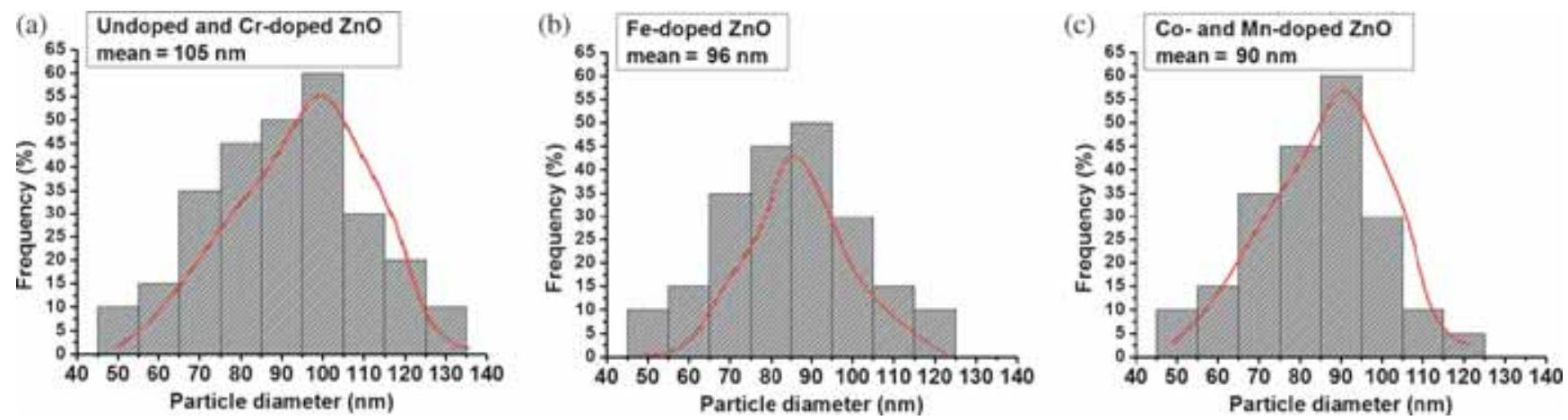

Figure 2. Diameter size distribution histograms of the NPs.
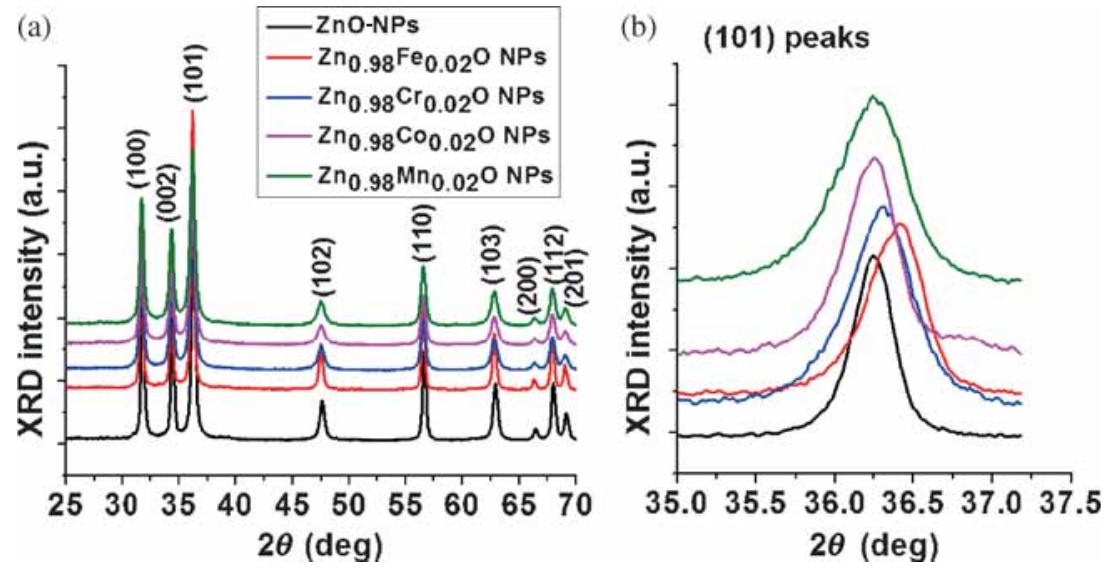

Figure 3. (a) XRD patterns of the undoped and TM-doped ZnO-NPs. (b) The (101) peaks of the samples.

Table 1. Calculated lattice constants and crystallite size of grown pure $\mathrm{ZnO}$ and $\mathrm{TM}$-doped $\mathrm{ZnO}$ at $500^{\circ} \mathrm{C}$ using $\mathrm{XRD}$ patterns.

\begin{tabular}{|c|c|c|c|c|c|c|c|}
\hline Sample & $\begin{array}{l}\text { FWHM } \\
(101) \\
\text { (degree) }\end{array}$ & $\begin{array}{c}\text { Peak } \\
\text { position } \\
\text { (degree) }\end{array}$ & $\begin{array}{l}\text { Inter-planar } \\
\text { spacing }(\AA) \\
\text { for }(101)\end{array}$ & $\begin{array}{l}\text { Crystallite size }(\AA) \\
\text { (Scherrer equation) }\end{array}$ & Lattice parameter $(\AA)$ & $\begin{array}{l}\text { Crystallite } \\
\text { size }(\AA) \\
\text { SSP method }\end{array}$ & $\varepsilon \times 10^{-4}$ \\
\hline $\mathrm{ZnO}$ & 0.29 & 36.244 & 2.4787 & 47.52 & $a=3.2500$ and $c / a=1.60$ & 84.26 & 2.94 \\
\hline $\mathrm{Zn}_{0.98} \mathrm{Fe}_{0.02} \mathrm{O}$ & 0.31 & 36.306 & 2.474 & 44.44 & $a=3.2418$ and $c / a=1.61$ & 70.75 & 3.18 \\
\hline $\mathrm{Zn}_{0.98} \mathrm{Cr}_{0.02} \mathrm{O}$ & 0.32 & 36.410 & 2.468 & 47.70 & $a=3.2345$ and $c / a=1.62$ & 96.15 & 3.23 \\
\hline $\mathrm{Zn}_{0.98} \mathrm{Co}_{0.02} \mathrm{O}$ & 0.36 & 36.250 & 2.478 & 38.27 & $a=3.2518$ and $c / a=1.60$ & 58.59 & 2.95 \\
\hline $\mathrm{Zn}_{0.98} \mathrm{Mn}_{0.02} \mathrm{O}$ & 0.40 & 36.241 & 2.479 & 34.45 & $a=3.2499$ and $c / a=1.60$ & 60.48 & 3.14 \\
\hline
\end{tabular}

crystallite size in nanometres, $\lambda$ the wavelength of the radiation (1.54056 $\AA$ for $\mathrm{CuK} \alpha$ radiation), $k$ a constant equal to $0.94, \beta_{h k l}$ the peak width at half-maximum intensity and $\theta$ the peak position. According to the Scherrer equation, crystallite size is sorted: $D_{\text {Cr-doped }}>D_{\text {undoped }}>D_{\text {Fe-doped }}>$ $D_{\text {Co-doped }}>D_{\text {Mn-doped }}$.

It is known that some parameters affect the peak width and the most important of these parameters is lattice strain. There are a number of methods used to calculate the effect of lattice strain on broadening of the lattice diffraction peaks such as the Williamson-Hall and size-strain plot (SSP) methods [16]. The SSP method is more accurate, especially at higher diffraction angles. Therefore, the crystallite size and lattice strain of the samples are calculated using SSP method. In this method, the peak broadening due to the lattice strain is estimated from $\varepsilon=\beta_{\mathrm{s}} / \tan \theta$ [16]. Therefore, the total broadening is obtained from

$$
\beta_{h k l}=\beta_{\mathrm{s}}+\beta_{\mathrm{D}},
$$

where $\beta_{\mathrm{D}}$ is the peak broadening that is corresponding to crystallite size. According to the SSP method, the relation between lattice strain and crystallite size is given by:

$$
\left(d_{h k l} \beta_{h k l} \cos \theta\right)^{2}=\frac{A}{D}\left(d_{h k l}^{2} \beta_{h k l} \cos \theta\right)+\left(\frac{\varepsilon}{2}\right)^{2},
$$


where $A$ is a constant, equal to $3 / 4$ for the spherical shape samples used in this experiment. In figure 4 , the term $(d \beta \cos \theta)^{2}$ is plotted with respect to $\left(d^{2} \beta \cos \theta\right)$ for all the diffraction peaks of undoped and TM-doped ZnO-NPs from $2 \theta=25-70^{\circ}$. The crystallite size and strain can be obtained from the slope and root of the $y$-intercept of the linearly fit data, respectively. According to SSP method, the crystallite size and strain of the NPs are sorted: $D_{\text {Cr-doped }}>D_{\text {undoped }}>$ $D_{\text {Fe-doped }}>D_{\text {Mn-doped }}>D_{\text {Co-doped }}$ and $\varepsilon_{\text {Cr-doped }}>\varepsilon_{\text {Fe-doped }}>$ $\varepsilon_{\text {Mn-doped }}>\varepsilon_{\text {Co-doped }}>\varepsilon_{\mathrm{ZnO}}$. It can be seen that the arrangement of $D$ is approximately the same in two methods. Furthermore, this arrangement is in good agreement with the SEM images. In addition, $\mathrm{Cr}$ with smaller ionic radius creates bigger strain in comparison to the other samples.

Figure 5a-d shows results of high-resolution N(E) Auger electron spectroscopy of $\mathrm{Cr}, \mathrm{Fe}, \mathrm{Mn}$ and $\mathrm{Co}$, respectively. As illustrated in figure 5a, two Cr peaks at 476 and $485 \mathrm{eV}$ are evident for the Cr-doped $\mathrm{ZnO}-\mathrm{NPs}$. These correspond

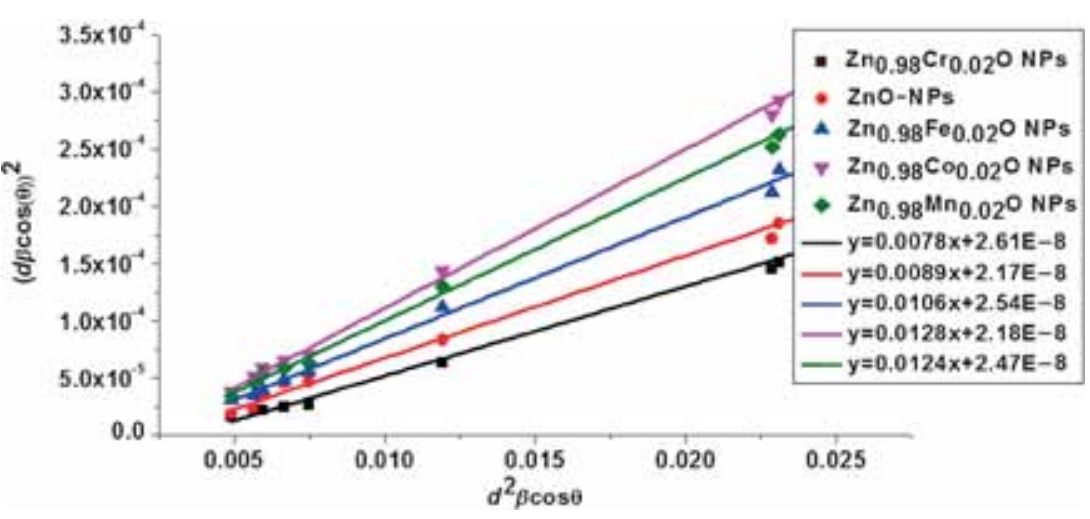

Figure 4. SSP plot of the undoped and TM-doped ZnO-NPs. The crystallite size is achieved from the slope of the linearly fit data, while the root of the $y$-intercept gives the strain.
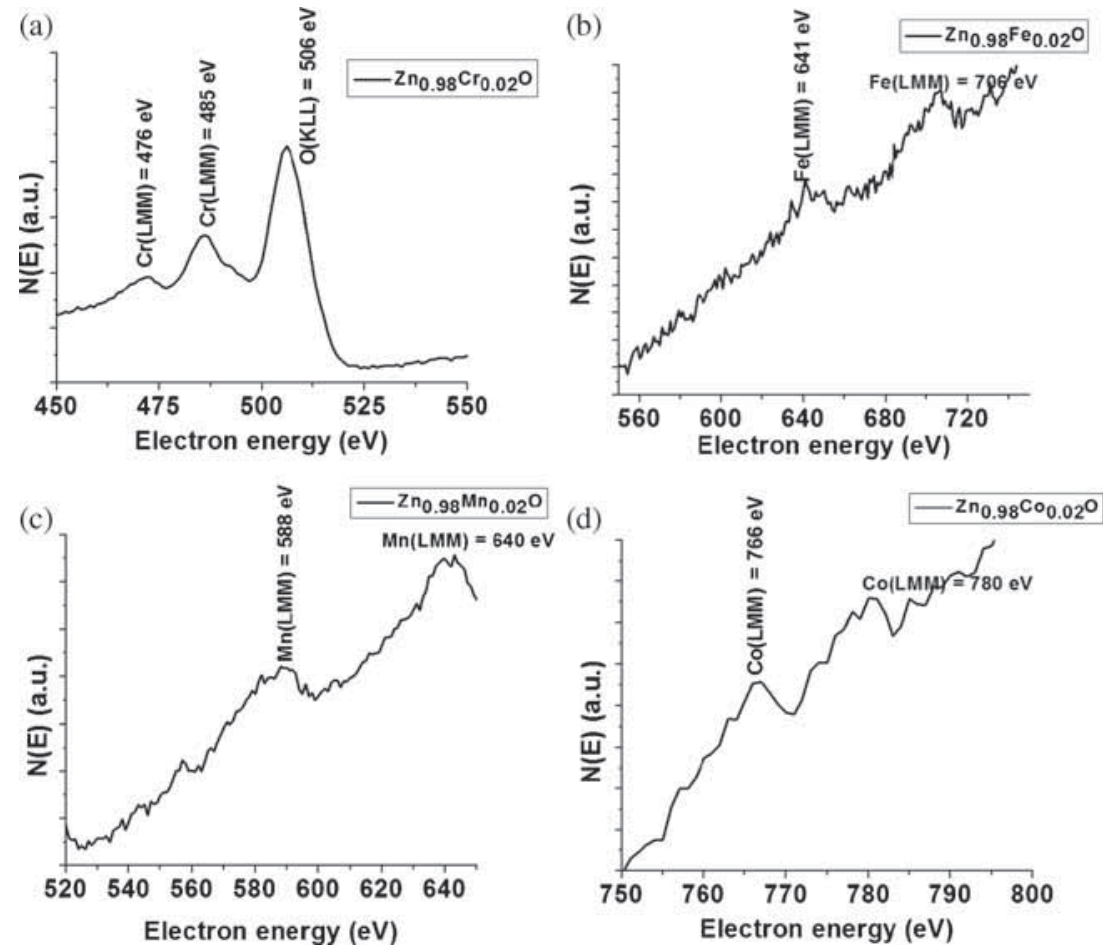

Figure 5. High-resolution N(E) Auger electron emission spectroscopy of the TMdoped $\mathrm{ZnO}$ nanoparticles: (a) chromium spectrum, (b) iron spectrum, (c) manganese spectrum and (d) cobalt spectrum corresponding to LMM Auger electron emissions from chromium, iron, manganese and cobalt, respectively. 


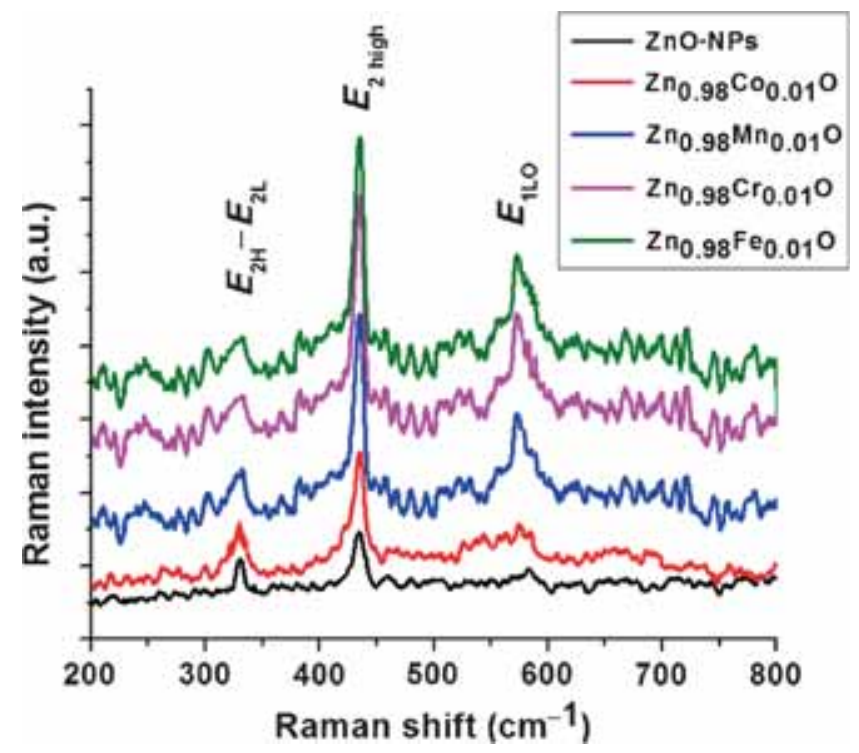

Figure 6. Raman spectra of the undoped and TM-doped ZnO-NPs. to MLL Auger electron emissions from the chromium. Figure 5b shows two peaks at 641 and $706 \mathrm{eV}$ that indicate MLL Auger electron emissions from the iron. The FEAES spectrum of Mn-doped $\mathrm{ZnO}-\mathrm{NPs}$ is shown in figure 5c. It also includes two peaks at 588 and $640 \mathrm{eV}$ that correspond to LMM Auger electron emission from manganese. FEAES spectrum of Co-doped also reveals two peaks at 766 and $780 \mathrm{eV}$ that belong to LMM Auger electron emission from cobalt. The FEAES results show that the concentrations of dopant materials are the same for all samples. Such peaks from the FEAES and XRD results provide strong evidence for successful Cr-, Fe-, Mn- and Co-doped in ZnO-NPs.

Raman scattering at room temperature was carried out to investigate the vibrational mode and influence of TM doping on $\mathrm{ZnO}$ nanostructure. Raman spectroscopy is an effective technique for estimating the crystallinity of materials. According to the group theory, single crystalline $\mathrm{ZnO}$ belongs to the $C_{6 V}^{4}(\mathrm{P} 63 \mathrm{mc})$ space group, having two formula units per primitive cell and eight sets of optical phonon modes
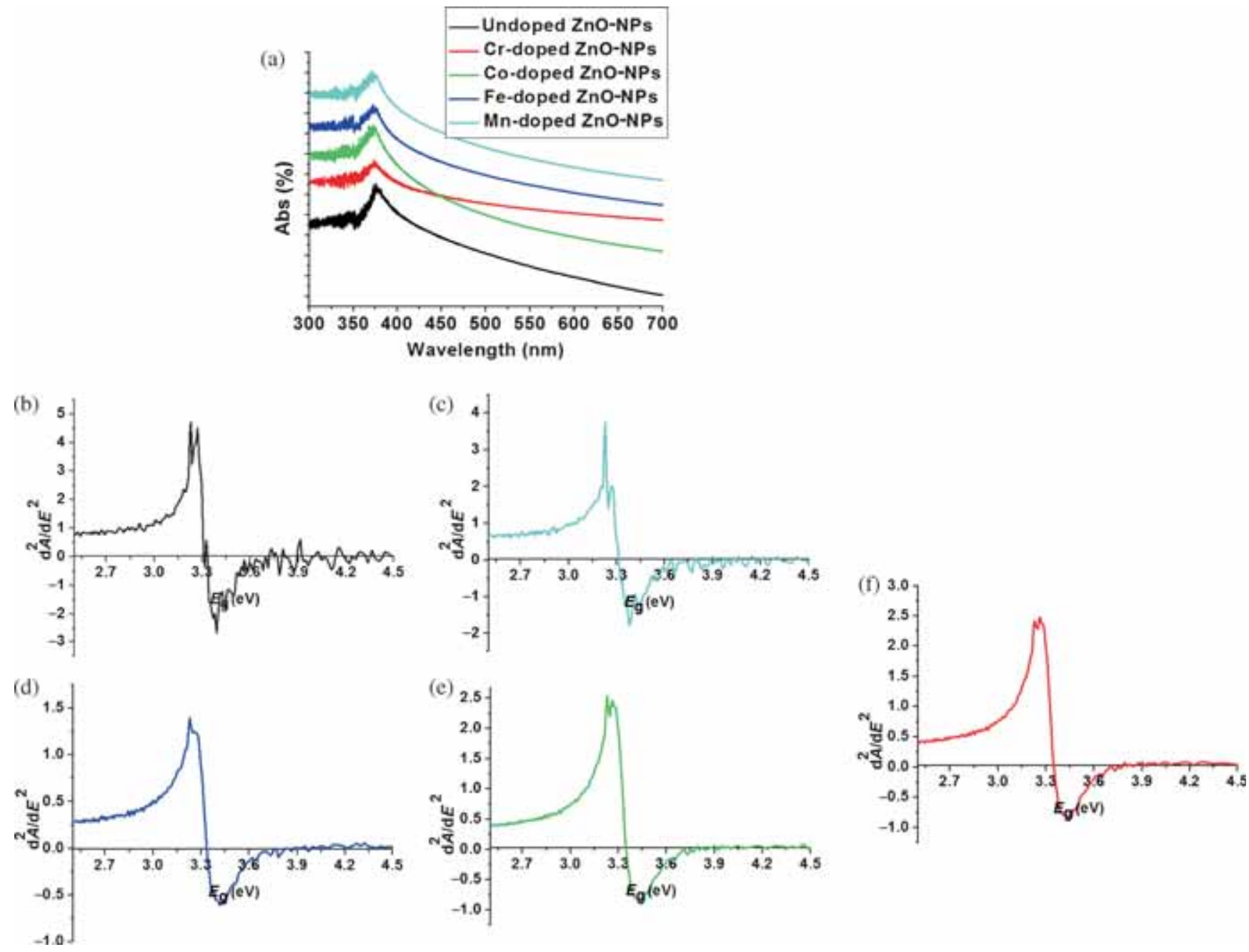

Figure 7. (a) Second derivative of the UV-Vis absorption spectra of the undoped and TM-doped ZnO-NPs. (b-f) The band gap of the undoped and TM-doped $\mathrm{ZnO}-\mathrm{NPs}$ estimated from second derivate and energy excel intersect. 
at the $\Gamma$ point of the Brillouin zone (BZ). The phonon modes at the $\mathrm{BZ}$ centre for hexagonal structure are given by:

$$
\Gamma=2 \mathrm{~A}_{1}+2 \mathrm{E}_{1}+2 \mathrm{E}_{2}+2 \mathrm{~B}_{1},
$$

which is $\mathrm{A}_{1}+\mathrm{E}_{1}+2 \mathrm{E}_{2}$ modes are Raman active, $\mathrm{A}_{1}+\mathrm{E}_{1}$ modes are infrared (IR) active and $\mathrm{B}_{1}$ modes are silent (neither Raman nor IR active). The $A_{1}$ mode is polarized parallel to the $C$-axis and the $\mathrm{E}_{1}$ mode is polarized perpendicular to the $C$-axis, and both split into transverse optical (TO) and longitudinal optical (LO) branches; the $\mathrm{E}_{2 \mathrm{H}}-\mathrm{E}_{2 \mathrm{~L}}$ mode exhibits the presence of undoped $\mathrm{ZnO}$ that can only be found when the $\mathrm{ZnO}$ is a single crystal. The $\mathrm{E}_{2}$ (high) mode of the Raman active mode is a characteristic peak for the wurtzite hexagonal phase of $\mathrm{ZnO}$. The $\mathrm{E}_{1}$ (LO) mode is associated with impurities and formation defects such as oxygen vacancies. The Raman spectra of nanoparticles with different TM dopants are shown in figure 6 . The peaks around $330 \mathrm{~cm}^{-1}$ for different dopant indicates the $\mathrm{E}_{2 \mathrm{H}}-\mathrm{E}_{2 \mathrm{~L}}$ (multi-phonon process) mode, which determines that the nanoparticles are single crystals. This peak for Mn-doped ZnO-NPs is sharper in comparison with the other samples indicating that most of the Mn-doped ZnO-NPs are single crystals. All spectra show a sharp and strong peak at around $434 \mathrm{~cm}^{-1}$ that is assigned to $E_{2}$ (high) mode and it is a characteristic peak of wurtzite hexagonal $\mathrm{ZnO}$, confirming that the TM-doped $\mathrm{ZnO}-\mathrm{NPs}$ have wurtzite hexagonal structure. The peak at $572.524,574.115,583.149$ and 583.149 for $\mathrm{Fe}, \mathrm{Co}, \mathrm{Cr}$ and $\mathrm{Mn}$, respectively, are referred to be $\mathrm{E}_{1}$ (LO) mode, confirming associated with the impurities and formation of defects such as oxygen vacancies that are increased by incorporating dopant. Thus, doped $\mathrm{ZnO}-\mathrm{NPs}$ with $\mathrm{Cr}$, $\mathrm{Co}, \mathrm{Fe}$ and $\mathrm{Mn}$ enhanced the oxygen vacancies. In fact, the Raman results show more oxygen vacancies for the samples with bigger strain.

The UV-Vis absorption spectra of the ZnO-NPs at room temperature are shown in figure $7 \mathrm{a}$. The spectra reveal a characteristic absorption peak for $\mathrm{ZnO}$ at wavelengths from 376 for the undoped $\mathrm{ZnO}$ to $373 \mathrm{~nm}$ for the doped. This can be attributed to the intrinsic band-gap absorption of $\mathrm{ZnO}$, owing to the electronic transitions from the valence band to the conduction band $\left(\mathrm{O}_{2 \mathrm{p}} \rightarrow \mathrm{Zn}_{3 \mathrm{~d}}\right)$. In addition, the direct band gap can be estimated from the maximum of the first derivative of the absorbance plot $v s$. energy also from intersection of the second derivative with energy axle as shown in figure $7 \mathrm{~b}-\mathrm{f}$ [17]. It can be seen that absorption peak is blue-shifted due to TM element. In fact, these elements as metal can increase electron concentration that cause to widen the band gap of $\mathrm{ZnO}-\mathrm{NPs}$.

\section{Conclusion}

Undoped and TM-doped ZnO-NPs were synthesized by the sol-gel method in gelatin media. The XRD results showed that all of the undoped and doped ZnO-NPs exhibited the hexagonal with a wurtzite structure. The SSP method and Scherrer equation showed the same arrangement for crystallite size of the samples that was in good agreement with the SEM results. In addition, the SSP results indicated a bigger strain and smaller strain for the Cr- and Co-doped $\mathrm{ZnO}$ NPs, respectively. The Raman results revealed that bigger strain caused to create more oxygen vacancy in the $\mathrm{ZnO}$ structure. Furthermore, the UV peaks of the TM-doped $\mathrm{ZnO}$ NPs showed a blue-shift in comparison to the undoped $\mathrm{ZnO}$ NPs. This blue-shift could show the donor behaviour of TM elements in $\mathrm{ZnO}$ lattice.

\section{Acknowledgements}

We would like to thank Shahid Chamran University of Ahvaz for financial support. R Yousefi gratefully acknowledges IAU for partially supporting this research work.

\section{References}

[1] Azarang M, Shuhaimi A, Yousefi R and Sookhakian M 2015 RSC Adv. 521888

[2] Azarang M, Shuhaimi A, Yousefi R and Sookhakian M 2014 J. Appl. Phys. 116084307

[3] Özgür Ü, Alivov YaI, Liu C, Teke A, Reshchikov M A, Doğan S et al 2005 J. Appl. Phys. 98041301

[4] Jamali-Sheini F, Yousefi R, Joag D S and More M A 2013 Mater. Lett. 111181

[5] Yousefi R 2015 Cryst. Eng. Comm. 172698

[6] Anghel J, Thurber A, Tenne D A, Hanna C B and Punnoosea A 2010 J. Appl. Phys. 107 09E314

[7] Khorsand Zak A, Majid W H A, Darroudi M and Yousefi R 2011a Mater. Lett. 6570

[8] Omri K, Najeh I, Dhahri R, El Ghoul J and El Mir L 2014 Microelectron. Eng. 12853

[9] Sahai A and Goswami N 2007 Ceram. Int. 4014569

[10] Vaezi M R and Sadrnezhaad S K 2007 Mater. Des. 28515

[11] Jamali-Sheini F, Yousefi R, Sa'aedi A and Huang N M 2014 Ceram. Int. 407737

[12] Park S B and Kang Y C 1997 J. Aerosol. Sci. 28 S473

[13] Ko T S, Yang S, Hsu H C, Chu C P, Lin H F, Liao S C et al 2006 Mater. Sci. Eng. B $\mathbf{1 3 4} 54$

[14] Zhou Y, Liu C, Zhong X, Wu H, Li M and Wang L 2014 Ceram. Int. 4010415

[15] Yousefi R, Muhamad M R and Khorsand Zak A 2010 Thin Solid Films 5185971

[16] Khorsand Zak A, Majid W H A, Abrishami M E and Yousefi R 2011b Solid State Sci. 13251

[17] Khorsand Zak A, Razali R, Majid W H A and Darroudi M 2011 Int. J. Nanomed. 61399 